\title{
Understanding Tradeoffs in the Context of Farm-Scale Impacts: An Application of Decision-Support Tools for Assessing Climate Smart Agriculture
}

\author{
Susan M. Capalbo, Clark Seavert, John M. Antle, Jenna Way, \\ and Laurie Houston
}

\begin{abstract}
Climate change and enhanced climate variability will have differing impacts on agricultural producers worldwide. The increasing utilization of precision farming and mobile technologies, together with improvements in data management software, offer expanding opportunities for an integrated data platform that links farm-level management decisions and corresponding behavioral changes to site-specific biophysical data and analytical tools. The goals of this paper are to illustrate how decision support tools can be designed to address the farm-scale economic and environmental tradeoffs associated with changes in climatic conditions and how these farm-scale tools could be linked with regional based analyses to scale up to the information needed for better science-based policy.
\end{abstract}

We use the AgBiz Logic ${ }^{\mathrm{TM}}$ platform to evaluate farm-scale climate smart options for the dryland wheat producing area of the U.S. Pacific Northwest. A software tool like AgBiz Logic could also be utilized to provide higher quality, more timely data for landscape-scale and regional technology assessment. Decision support tools are at the very heart of the recommendations called for in the recent U.S. Government Accountability Office report 14-755 (U.S. GAO 2014), which speaks to USDA's ongoing efforts to better communicate information to growers in a timely downscaled manner.

S.M. Capalbo $(\bowtie) \bullet$ C. Seavert $\bullet$ J.M. Antle $\bullet$ J. Way $\bullet$ L. Houston College of Agricultural Sciences, Oregon State University, Corvallis, OR, USA e-mail: susan.capalbo@oregonstate.edu; john.antle@oregonstate.edu; jenna.way@oregonstate.edu 


\section{Introduction}

Climate change and enhanced climate variability will have differing impacts on agricultural sectors worldwide. Whether in the form of increased intra-seasonal variability, severe heat waves, long-term drought or warmer winters, farmers and growers need to be cognizant of the risks and opportunities that future weather patterns may bring to yields and profitability, as well as the possible environmental outcomes associated with changes in management regimes. Despite advances in applied research and analysis over the past half century, making informed management decisions based on integrating climate and environmental science findings at the farm scale remains a challenge. Critical information and data are often missing, and thus the consequences of changes in management practices across many dimensions are not easily identified.

Three key elements are required to improve the capability to make better management, and ultimately, policy decisions: (1) timely and accurate data on climate variability and its impact on yield and cost projections; (2) scientific understanding of the agro-ecological system at the farm scale; and (3) incorporation of those two elements into knowledge products that meet the needs of growers and policy decision makers. The increasing utilization of precision farming and mobile technologies, together with improvements in data management software, offer expanding opportunities for an integrated data platform that links farm-level management decisions and corresponding behavioral changes to site-specific biophysical data and analytical tools. Through the use of data technologies, farm-level information can be integrated with publically available data at the landscape scale for supporting science-based policy and sustainable management of agricultural landscapes.

The primary goal of this paper is to illustrate how decision support tools can be designed to address the farm-scale tradeoffs associated with changes in climatic conditions. We also explore how these farm-scale tools could be linked with regional based analyses to scale up to the information needed for better science-based policy. We illustrate how the three key elements noted above can be addressed within the AgBiz Logic ${ }^{\mathrm{TM}}$ platform and decision-support framework developed to aid growers in evaluating current and alternative management systems under future climate scenarios. By incorporating both climate change and environmental outcomes, these decision tools can be used to evaluate climate smart options. Our illustrative case study reflects the dry-land wheat producing area of the U.S. Pacific Northwest.

Decision tools and modules such as $\mathrm{AgBiz}$ Logic, provide essential analytical output for global and national efforts labeled climate-smart agriculture (CSA) which focus on making farms and farmers more resilient to a changing climate. These decision support tools are at the very heart of the recommendations called for in the recent U.S. Government Accountability Office report 14-755 (U.S. GAO 2014), which speaks to USDA's ongoing efforts to better communicate information to growers in a timely downscaled manner. 


\section{AgBiz Logic as a Decision Support Tool for Addressing CSA}

AgBiz Logic is an integrated knowledge platform which collects and allocates grower data to enterprise budgets and saves the budgets. It also saves plans ${ }^{1}$ and scenarios which can in turn be used in the economic, financial, climate and environmental modules. A simplified schematic of AgBiz Logic is provided in Fig. 1. Climate data from climate models and projections; environmental location-specific data on soil, slopes, rainfall etc.; and site-specific production data and other regional (public) data on prices, costs and transportation information are part of the information-base used and stored by AgBiz Logic. Outputs from each of the AgBiz Logic modules are inputted into another component of the software tool and/or used to generate metrics and other economic information. The economic and financial calculators are the means for farmers to better understand how climate change may impact their livelihood and their on-farm assets. The components are explained in greater detail in this paper.

AgBiz Logic (available online at http://www.agbizlogic.com/) consists of the following economic and financial calculators:

- AgBizProfit ${ }^{\mathrm{TM}}$ is a capital investment tool that evaluates an array of short-, medium-, and long-term investments. The module uses the economic concepts of net present value, annual equivalence, and internal rate of return to analyze the potential profitability of a given investment.

- AgBizLease TM $^{\mathrm{TM}}$ is designed to help agricultural producers establish equitable short- and long-run crop, livestock and other capital investment leases. The module uses the economic concepts of net present value to analyze an equitable crop share or cash rent lease for a tenant and landowner.

- AgBizFinance ${ }^{\mathrm{TM}}$ is designed to help agricultural producers make investment decisions based on financial liquidity, solvency, profitability, and efficiency of the farm or ranch business. After an AgBizFinance analysis has been created, investments in technology, conservation practices, value-added processes, or changes to cropping systems or livestock enterprises can be added to or deleted from the current farm and ranch operation. Changes to a business' financial ratios and performance measures are also calculated.

Two recent additions to the AgBiz Logic decision support platform include the AgBizClimate ${ }^{\mathrm{TM}}$ and AgBizEnvironment ${ }^{\mathrm{TM}}$ modules:

- AgBizClimate delivers essential information about climate change to farmers and land managers that can be incorporated into projections about future net returns, via changes in expected yields. By using data unique to their specific farming operations, growers can develop management pathways that best fit their operations and increase net returns under alternative climate scenarios.

\footnotetext{
${ }^{1}$ Plans consist of a sequence of budgets that describe a particular management and or investment strategy. Plans can be compared to each other and saved as a scenario.
} 


\section{The AgBiz Logic ${ }^{T M}$ Platform}

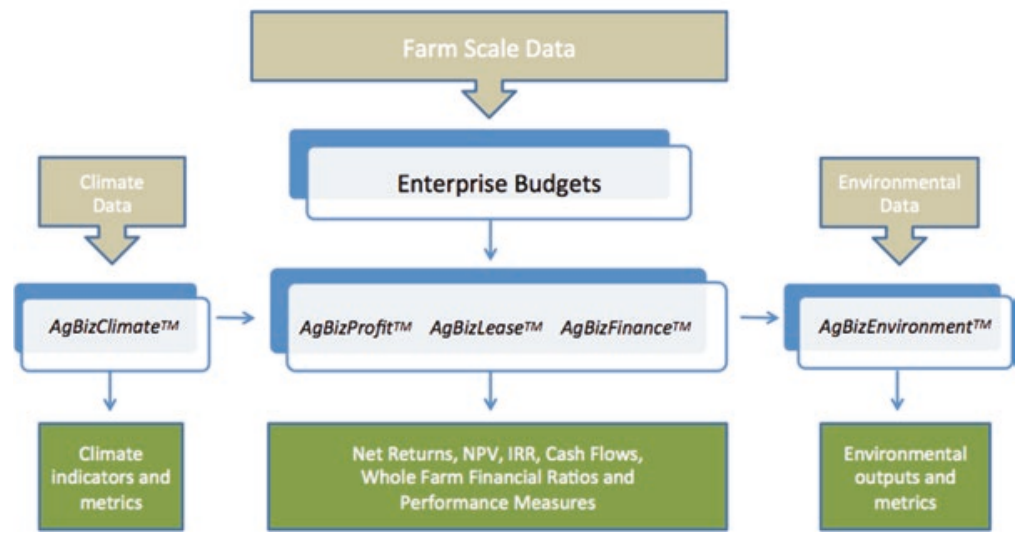

Fig. 1 AgBiz logic platform

- AgBizEnvironment uses environmental models and other ecological accounting to quantify changes in environmental outcomes such as erosion, soil loss, soil carbon sequestration and GHG emissions resulting in the ability to incorporate on-farm and off-farm environmental outcomes into the decision support software and platform.

The AgBiz Logic platform provides both a farmer-level decision support tool and an assessment tool for researchers to realistically determine how climate change and climate change policies may influence and impact regional agricultural sectors. By incorporating regional downscaled climate change information, farm management and financial information, and on-and-off farm environmental impacts of land use changes and management decisions into an interconnected online program, actions of growers and data needs of researchers are linked. The downscaled climate change information influences projected yield and production inputs that change over time. These yield changes are the impetus for producer-generated adjustments in input use, management, and technology adoption that may lessen negative impacts or take advantage of positive opportunities.

\section{Addressing the Farm-Scale Tradeoffs Associated with Changes in Climate}

AgBiz Logic provides an internally consistent framework for evaluating climate change impacts and investment decisions at the farm scale. Farmers, growers, and land managers can use AgBizClimate to explore near-term projections for average weather conditions (e.g., growing degree days, chilling days) relevant to a 
commodity in their area. With knowledge of these projected changes, users have an opportunity to adjust their investments, yields and production inputs based on how such changes will affect their production and risk. AgBizClimate linked to AgBiz Logic allows users to step into the world of 20-30 years from present and consider how their current enterprises and operations would continue to serve them in the future, and whether there are any long-range planning decisions they may want to begin considering in order to maintain profitable operations.

What follows is an example of a case study in the mid-Columbia region of Umatilla County, Oregon using modules in the AgBiz Logic suite to observe the outcomes of climate change on current and alternative cropping systems (rotation) and on net returns (Seavert et al. 2012). We will first present an example of how AgBizClimate can be used to evaluate climate change impacts with changes in yields, tractor, combine and truck costs and production inputs, and we will also demonstrate how the AgBizProfit module can be used to evaluate investment decisions associated with changing a crop rotation.

\subsection{Initial Setup and Baseline Scenario}

The farm operation is a typical 3800-acre dryland wheat farm, in a region that receives between 12 and 18 inches of precipitation annually. In keeping with common practice, the producer uses a winter wheat and fallow crop rotation that includes direct seeding and chemical fallow to conserve soil moisture, increase wheat yields, reduce soil erosion, and reduce fuel usage. Weeds are controlled with glyphosate in the fallow years and other herbicides as needed during the crop years. Pesticides are applied as necessary. Fertilizer requirements are applied at planting using a directseed drill. The farm's average yield for winter wheat is 49.5 bushels per acre. Onehalf of the acres are leased and the farm operator owns the remaining acres. The leased land is based on the landowner receiving one-third of the crop and paying one-third of the weed control, fertilizer, and crop insurance costs (hail, fire and crop revenue coverage) and $100 \%$ of the property insurance and taxes. The yield levels are consistent with the yields from the 2007 USDA Agricultural Census for this area.

The data input needs and sequencing of steps are summarized in Appendix A. The producer selects previously generated crop and livestock enterprise budgets from $\mathrm{AgBiz}$ Logic; if these are not specific to this operation a grower can choose from a set that best reflects their returns and costs (Appendix A, Fig. 5). These previously generated/selected budgets serve as the baseline net returns scenario for comparison once weather variables are introduced. AgBizClimate is then used to select the weather station that is closest to the crop or livestock enterprises (Fig. 6). The result is downscaled, site-specific weather forecast information for the producer to use to best assess how climate change will impact the farm or enterprise.

After selecting the weather station in closest proximity to the farmed acres, the producer can select up to three weather variables that he/she believes will most 
impact wheat yields (Fig. 7). In this example, the number of nights below freezing, accumulated growing degree days and accumulated seasonal precipitation are chosen. Each weather variable has its own specific impacts, as shown in Appendix A, Figs. 8, 9, and 10. The modeled baseline weather condition (black line in Figs. 9 and 10 ) is an average for each weather variable chosen from 1970 to 1999 . The modeled future climate variable is averaged over 2030-2059 for high and low emission scenarios. The solid red and yellow lines show the average, and the shading shows the 5-95th percentile range of resulting from 20 climate models (Figs. 10 and 11).

By the 2030s, the frequency of nights below freezing per year is expected to decrease by 29 nights for the low emissions future and by 34 nights for the high emissions future, as compared with the historical baseline (Fig. 8). From this information, predictions can be made regarding how wheat yields will be impacted from this specific weather variable, using either crop models or grower/expert estimates. In this example yields are increased $20 \%$ due to fewer nights below freezing; sensitivity analysis on fluctuations in yields can be incorporated into future analyses.

Figure 9 shows the results for changes in the number of growing degree days. By the 2030s, accumulated growing degree days from April 1 to October 31 are expected to increase by $525^{\circ}$ hours for the low emissions future and by 620 degree hours for the high emissions future, as compared with the historical baseline. From this information, wheat yields are estimated to increase $15 \%$ due to a higher number of accumulated degree days above 50. Figure 10 shows the results for accumulated precipitation by month. Accumulated water year precipitation is expected to increase by 0.4 inches both for the low emissions and for high emissions future, as compared with the historical baseline. From this information, the producer estimates wheat yields will increase $25 \%$ due to an increase in precipitation combined with the time of year of the precipitation.

In Fig. 11, the producer can choose (observe from the available data) how likely his/her wheat yields will be impacted based on Crop Models, Grower Focus Groups, and from their own estimates of yields from Figs. 8, 9, and 10. The producer then enters a final yield estimate for each budget ("Your Changes"). This value will be leveraged to modify each budget used in the analysis. In the example shown, the user agrees with the Crop Models of an increase in wheat yields of 20.3\%. However, the user also inserts an additional wheat budget and uses the Grower Focus Group value of $15.0 \%$ as a comparison. In $\mathrm{AgBizClimate}$ users can create new budgets by modifying selected inputs that are directly related to yields (Fig. 12). Examples of changing inputs related to yields include custom harvesting of hay or wheat crops, when paid by the ton.

\subsection{Exploring Climate Change Impacts and Investments in Alternative Cropping Systems}

Next, we evaluate the impact these changes in yields have on net returns. We also explore the profitability of changing the cropping system. For this region, research suggests that growers may benefit from climate change when they 
adapt to an annual cropping system of winter wheat and camelina. Camelina is a crop being studied for its potential use as a source of biodiesel fuel for aviation, particularly in regions where dryland cropping systems are predominant.

Using the AgBizProfit module we can run a scenario report (using the budgets that were modified using AgBizClimate). Each scenario consists of one to five individual plans that can be compared to each other simultaneously. In this case we compare four plans: (1) the current 2015 winter wheat fallow plan, (2) a winter wheat fallow plan with a $20 \%$ increase in wheat yields, (3) a winter wheat fallow plan with a $15 \%$ increase in wheat yields, and (4) a change from a winter wheat fallow system to a winter wheat and camelina rotation. On the latter cropping system wheat yields will decline from 50 to 39 bushels per acre (or about 13\%) due to reduced soil moisture; however the revenues associated with the decline in wheat yields will be offset by the new revenues from the camelina crop. New crop budgets for these plans will be created for this scenario.

Table 1 reflects the yield changes under each scenario and shows how tractor, combine and machinery hours, truck miles driven, and expected years of life change as a result of the increased volumes of grain, annual acres harvested and the requirement of an additional combine when changing to an annual cropping system with camelina. ${ }^{2}$ For the winter wheat and camelina rotation, an average camelina yield of 36 bushels (1800 lbs) per acre is used and the market price is $\$ 0.15 / \mathrm{lb}$; camelina is assumed to be grown in place of fallow. Even though the wheat yields are much less (38.71 bushels per acre, Table 1) and machinery costs higher (crop farming 3800 acres annually as compared to 1900 with the wheat and fallow rotation), the contributions to net returns from camelina compensate for the loss in wheat net returns.

Each of the winter wheat and fallow rotations in 2040 include the additional costs due to increased incidences of weeds, disease and insect infestations attributed to warmer temperatures and higher precipitation. Two additional applications ( 1 additional herbicide application and the addition of a pesticide application) with material costs are included as well as costs per acre for materials to control insects and diseases. These additional applications increase the tractor and sprayer hours in the wheat and fallow rotations in 2040. However, when camelina is included in an annual cropping system the applications and material costs for four herbicides are removed, which greatly reduces annual tractor and sprayer hours.

The AgBizClimate results for per acre returns, total variable cash costs, and net returns of the four cropping systems with crops grown on both owned and leased land are shown in Table 2. The winter wheat and fallow rotation in 2015 has an average net return of $\$ 72$ per acre on owned land and a $\$ 36$ per acre on

\footnotetext{
${ }^{2}$ Camelina is more difficult to harvest than wheat and combines must slow down to three miles per hour (as opposed to six mph when harvesting wheat), reducing the number of acres harvested in a day and thus requiring the purchase of an additional combine, or custom hiring the additional harvesting.
} 


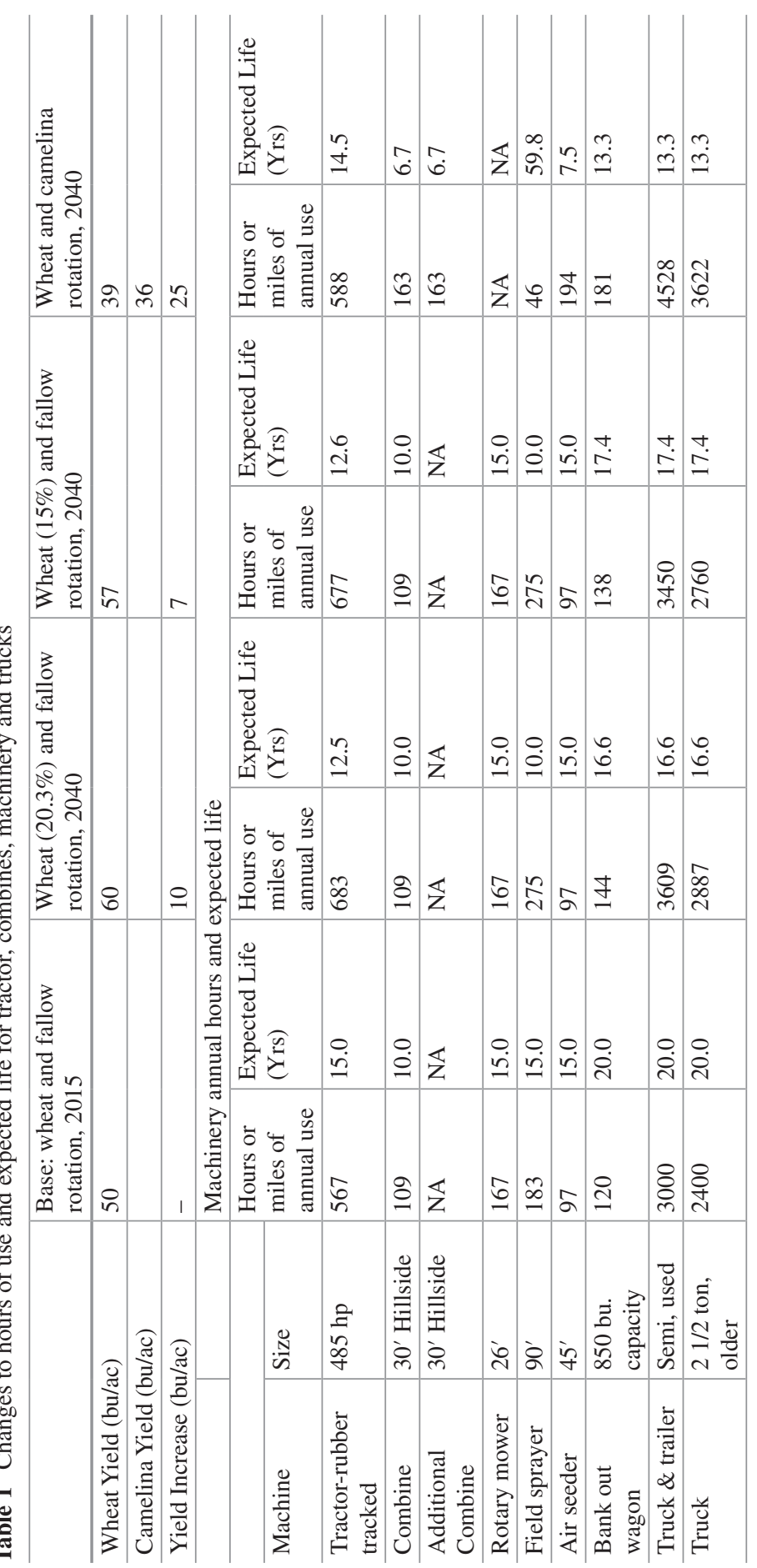


Table 2 Per acre returns, total variable cash costs, and net returns for winter wheat and fallow rotations and winter wheat and camelina annual cropping system for crops grown on owned and leased land

\begin{tabular}{|c|c|c|c|c|c|c|c|c|}
\hline \multicolumn{9}{|c|}{ Crops grown on owned land } \\
\hline & \multicolumn{2}{|l|}{2015} & \multicolumn{2}{|l|}{2040} & \multicolumn{2}{|l|}{2040} & \multicolumn{2}{|l|}{2040} \\
\hline & $\begin{array}{l}\text { Winter } \\
\text { wheat }\end{array}$ & Fallow & $\begin{array}{l}\text { Winter } \\
\text { wheat } \\
(20.3 \%)\end{array}$ & Fallow & $\begin{array}{l}\text { Winter } \\
\text { wheat } \\
(15 \%)\end{array}$ & Fallow & $\begin{array}{l}\text { Winter } \\
\text { wheat }\end{array}$ & Camelina \\
\hline Returns & $\$ 322$ & $\$ 0$ & $\$ 387$ & $\$ 0$ & $\$ 370$ & $\$ 0$ & $\$ 252$ & $\$ 270$ \\
\hline $\begin{array}{l}\text { Total } \\
\text { variable } \\
\text { cash } \\
\text { costs }\end{array}$ & $\underline{118}$ & $\underline{61}$ & $\underline{130}$ & $\underline{71}$ & $\underline{130}$ & $\underline{71}$ & $\underline{135}$ & $\underline{151}$ \\
\hline $\begin{array}{l}\text { Net } \\
\text { returns }\end{array}$ & $\$ 204$ & $(\$ 61)$ & $\$ 257$ & $(\$ 71)$ & $\$ 240$ & $(\$ 71)$ & $\$ 116$ & $\$ 119$ \\
\hline $\begin{array}{l}\text { Average } \\
\text { net } \\
\text { returns }\end{array}$ & \multicolumn{2}{|l|}{$\$ 72$} & \multicolumn{2}{|l|}{$\$ 93$} & \multicolumn{2}{|l|}{$\$ 85$} & \multicolumn{2}{|l|}{$\$ 118$} \\
\hline \multicolumn{9}{|c|}{ Crops grown on leased land } \\
\hline & \multicolumn{2}{|l|}{2015} & \multicolumn{2}{|l|}{2040} & \multicolumn{2}{|l|}{2040} & \multicolumn{2}{|l|}{2040} \\
\hline & $\begin{array}{l}\text { Winter } \\
\text { wheat }\end{array}$ & Fallow & $\begin{array}{l}\text { Winter } \\
\text { wheat } \\
(20.3 \%)\end{array}$ & Fallow & $\begin{array}{l}\text { Winter } \\
\text { wheat } \\
(15 \%)\end{array}$ & Fallow & $\begin{array}{l}\text { Winter } \\
\text { wheat }\end{array}$ & Camelina \\
\hline Returns & $\$ 215$ & $\$ 0$ & $\$ 258$ & $\$ 0$ & $\$ 247$ & $\$ 0$ & $\$ 168$ & $\$ 216$ \\
\hline $\begin{array}{l}\text { Total } \\
\text { variable } \\
\text { cash } \\
\text { costs }\end{array}$ & $\underline{93}$ & $\underline{49}$ & $\underline{105}$ & $\underline{57}$ & $\underline{106}$ & $\underline{57}$ & $\underline{111}$ & $\underline{135}$ \\
\hline $\begin{array}{l}\text { Net } \\
\text { returns }\end{array}$ & $\$ 121$ & $(\$ 49)$ & $\$ 153$ & $(\$ 57)$ & $\$ 141$ & $(\$ 57)$ & $\$ 57$ & $\$ 81$ \\
\hline $\begin{array}{l}\text { Average } \\
\text { net } \\
\text { returns }\end{array}$ & \multicolumn{2}{|l|}{$\$ 36$} & \multicolumn{2}{|l|}{$\$ 48$} & \multicolumn{2}{|l|}{$\$ 42$} & \multicolumn{2}{|l|}{$\$ 69$} \\
\hline
\end{tabular}

leased land. The low net returns are largely due to the wheat yield of 49.50 bushels per acre. Now consider the impacts of a changing climate, which in this example result in increased wheat yields. When yields are increased $20.3 \%$ in 2040 to 59.55 bushels, the net returns increase to $\$ 93$ per acre on owned land and $\$ 48$ per acre on leased land; these net returns must also be adjusted to reflect the increase in herbicides and insecticide application costs. We also provide the results for a smaller change in yields due to climatic changes. As expected net returns decrease slightly when wheat yields are increased only $15 \%$ relative to the 2015 crop rotation. The net returns are $\$ 85$ per acre on owned land and $\$ 42$ per acre on leased land.

To explore some of the tradeoffs that may be present under climate change we incorporate the profitability of changing the cropping system or adapting manage- 
Name of Scenario:

Climate Change Impacts on Current and Potential Annual Cropping System

Notes for this Scenario:

Observing the before and after effects of climate change on per acre net returns of growing a winter wheat $\&$ fallow rotation and a winter wheat \& Camelina annual cropping system in 2040

View results as a:

Table

Graph

Financial measure: Net Returns

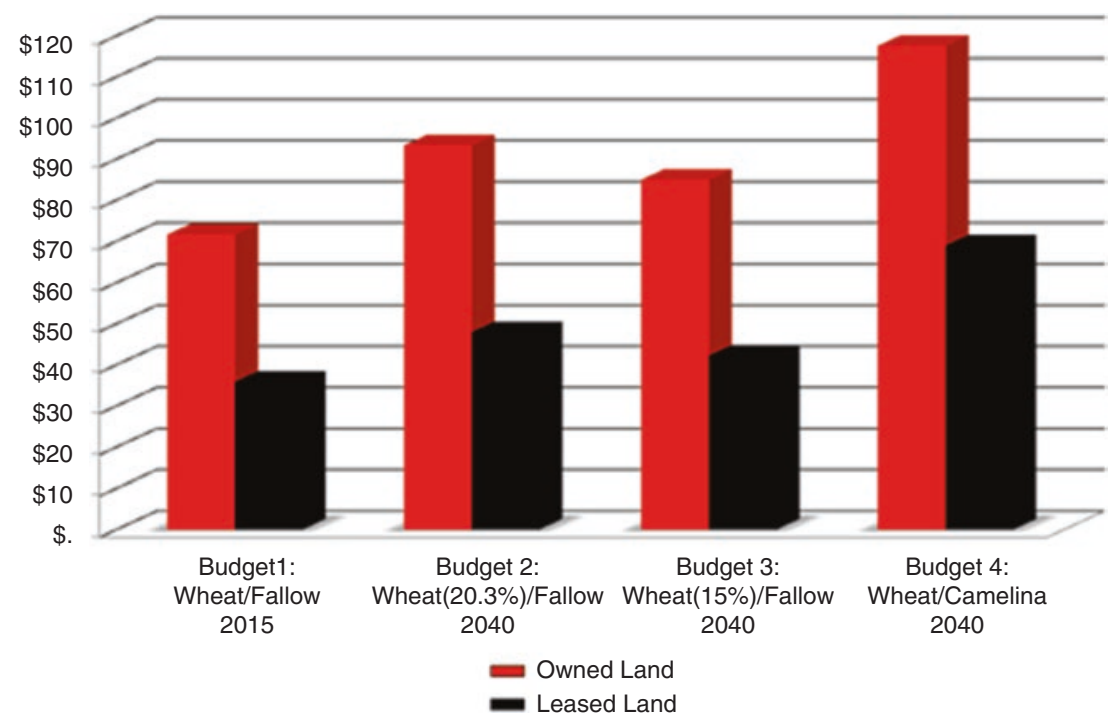

Fig. 2 AgBizClimate output results

ment to new climatic conditions. For this region, research suggests that growers may benefits from climate change when they adapt to an annual cropping system of winter wheat and camelina. The net returns with a winter wheat and camelina rotation are $\$ 117$ per acre on owned land and $\$ 69$ per acre with leased land. ${ }^{3}$ Figure 2, shows these results as an AgizClimate output. Sensitivity of net returns to output and input prices are available from the authors but not reported in this paper.

As shown in this illustrative example both cropping systems (winter wheat/fallow versus winter wheat/camelina) and cropping arrangements (owned versus

${ }^{3}$ Crop leases change in the mid-Columbia region with oilseed crops. The landowner receives $20 \%$ of the crop and pays $20 \%$ of the fertilizer costs and $100 \%$ of the property insurance and taxes. It should also be noted that herbicides are not used in the production of camelina. 
leased) will impact net returns. While many alternative cropping systems can be simulated, we provided only the comparison with the winter wheat/camelina and the original system currently used by a majority of the growers in this region. In both the owned and leased situations, both of which are typical of the arrangements in this area, the net returns per acre are higher with the effects of climate change for winter wheat and camelina annual rotation, regardless of whether the crops are grown on owned or leased land.

\subsection{Profitability of Implementing Investment Strategies}

Though we have shown that the winter wheat and camelina rotation has higher average net returns, we do not yet know if it is profitable for an individual producer. In order to switch to an annual cropping system that includes camelina, the producer would need to invest in an additional combine and truck. The profitability of this investment will depend on the timing of the cash flows. An alternative would be to custom hire the harvest of the camelina crop, which eliminates the need for the capital outlay of equipment, but also adds a certain amount of risk due to the uncertainty of the custom operator being available at harvest time. Selecting investments that will improve the financial performance of the business involves two fundamental tasks: (1) economic profitability analysis and (2) financial feasibility analysis. Economic profitability will show if an alternative is economically profitable. However, an investment may not be financially feasible: that is, the cash flows may be insufficient to make the required principal and interest payments (Boehlje and Ehmke 2005). In addition agricultural leases may also change with adaptation strategies as additional inputs and costs are incurred by either the landowner or tenant. The more a tenant or landowner contributes to total costs over the length of a lease, the higher the percentage share of the crop return or annual cash rent payment.

Figure 3 is an AgBizProfit output showing the results of a capital investment analysis for the adaptation strategies. Based on a discount rate of $4 \%$ and a 7 year analysis, the current wheat and fallow rotation has a net present value (NPV) of \$57 per acre. The NPV of the annual cropping system with the purchase of an additional combine and truck is $\$ 500 /$ acre. Custom harvesting of the camelina crop results in an NPV of $\$ 350$ per acre. Therefore, the annual cropping system with the additional equipment purchases is the most profitable strategy. However, if a producer does not have the required cash flow to invest in additional equipment, which is needed for this cropping system, then this change in cropping rotations may not be feasible. The AgBizFinance module can be used to determine the feasibility of switching to a camelina rotation.

Conducting an AgBizFinance analysis requires a detailed balance sheet, description of current loans, capital leases and cash flows for each enterprise in the farm business. This type of analysis is very specific to a particular farm and difficult to demonstrate and discuss without sufficient data. Therefore an AgBizFinance analysis and further discussion is not presented in this paper. 


\section{Name of Scenario:}

\section{Protitability of Changing to an Annual Cropping System on Owned Land}

Notes for this Scenario:
$\begin{aligned} & \text { Assessing the profitability of changing from a winter wheat and fallow rotation to an } \\ & \text { annual cropping system of winter wheat and cameina, with purchasing additional } \\ & \text { combine and truck or custom hiring harvest. }\end{aligned}$
\[ \begin{array}{l}\text { View results as a: } \\ \begin{array}{l}\text { Table, single plan \& all years OGraph, single plan \& all years } \\ \text { Table, all plans \& single year OGraph, all plans \& single year }\end{array}\end{array} \]

Investment Scenario

Net Present Values

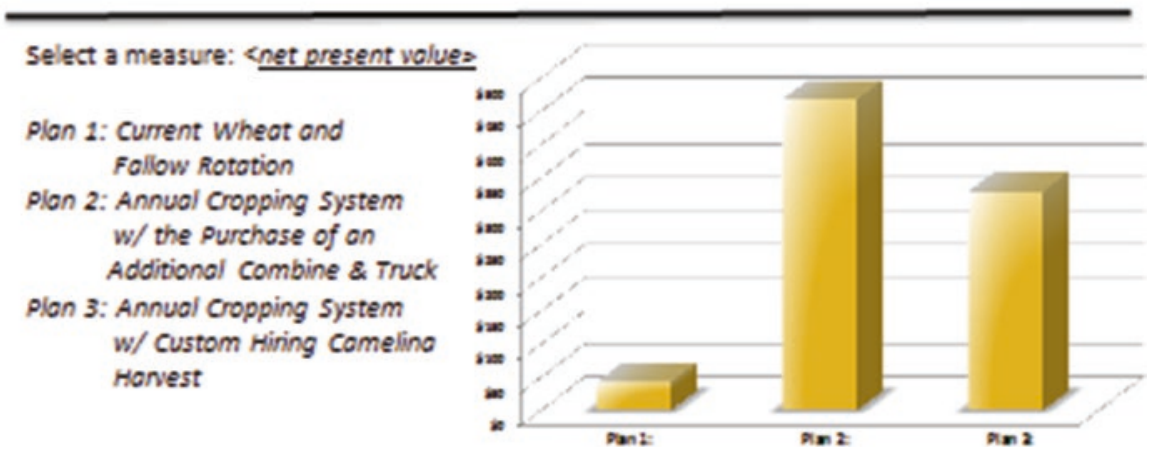

Fig. 3 AgBizProfit results for owned land

\subsection{Assessing Climate Change Implications for Agricultural Leases}

Most of agricultural leases today are based upon what has been done historically or customary for a region. However, as profit margins narrow and climate change impacts yields, production inputs, and crop rotations, there will be a greater focus to base future leases on equitability, where the tenant and landowner are compensated more evenly for their contributions into the lease. Determining the equitability of leases can be explored with a decision support tool such as AgBizLease, a module within AgBiz Logic. Often times, the net returns on leased land do not equitably compensate the tenant for their financial risk of farming the land. For example, under existing practices, equitable crop leases are established on the percentage of each party's contribution to total costs (Seavert 1999). Using this tool, tenants could review lease terms to determine if current land leases would be equitable in the future. For example, if more insecticides and fungicides are required in future 
production systems due to a changing climate, those costs could be shared in the same percentages as share of the crop. AgBizLease could use the AgBizClimate budgets from these analyses to further evaluate the equitability of current lease terms as input costs change, and the resulting sensitivity of net returns.

As shown in Fig. 3, the current crop-share lease is equitable for this winter wheat fallow rotation, however is not profitable for either the tenant or landowner. The accumulated net returns for the tenant and landowner for a ten year lease is $-\$ 104$ and $-\$ 40$ per acre. The yields and prices are not sufficient to compensate the tenant for their production inputs and the landowner for their contributions of returns to land, property taxes and both sharing the fertilizer, herbicide and crop insurance costs. However, if this crop-share lease changed to an annual cropping system of winter wheat and camelina with the same sharing of crop and production inputs, both tenant and landowner benefit with $\$ 168$ and $\$ 216$ per acre, but not equitably. The AgBizLease program calculated an equitable crop-share lease to be $73 \%$ of the crop to the tenant and 23\% to the landowner. By sharing the crop based on their contributions to this annual cropping system, the tenant would receive $\$ 295$ per acre and landowner $\$ 89$ per acre (Fig. 3).

\section{Assessing Environmental Impacts}

AgBiz Logic modules are based on the premise that growers maximize net returns over time; the static short run net returns are captured as the difference between revenues and cash costs. Depending upon the scenario, revenues can be defined as revenues associated with selling conventional, market-oriented products or can be expanded to include other services that might be valued by the grower, such as soil carbon, green production, environmental footprint, or other sustainability or riskmanagement attributes.

To capture the environmental aspects of the production decision, including onsite and off-site impacts, the AgBizEnvironment module reflects one of several approaches depending upon whether the environmental impact is considered an input or an output to the production process. Environmental/land quality can be considered as an input into the production process (i.e. soil quality) and thus part of the "natural capital" that impacts growers' net returns. Environmental quality can also be considered as an output of the production process. Way (2015) describes three possible firm-level profit maximization approaches to capture environmental impacts: (1) a conventional approach where environmental quality is reflected in changes in the natural capital variables; (2) the case where changes in environmental characteristics are best reflected using a multiple output production approach; and (3) a constrained profit maximization approach where environmental regulations constrain the choices and production levels of the grower. Each of these approaches requires information on the environmental outcomes from the production processes and/or how these may impact growers' net returns. 
The AgBizEnvironment module utilizes existing environmental models or calculators to quantify the environmental outcomes and links this information either directly to net returns (if we can construct a shadow price or cost of the outcomes) or provides direct measures of environmental issues of concern such as changes in GHG emissions, soil erosion, carbon soil sequestration and energy usage. Examples include the Environmental Impact Quotient Value (EIQ) formula developed by Cornell University, Cool Farm Tool which measures GHG (carbon dioxide, nitrous oxide, and methane) emissions, COMET-farm which is a whole farm carbon and GHG accounting systems, and the Universal Soil Loss Equation (USLE) calculator and its many variations. Outputs from these models or calculators can be categorized as either an input to the production process and/or an (desirable or undesirable) output from the production process. GHG emissions and soil carbon credits are often characterized as outputs, although soil carbon can also be an input to the quality of the natural capital; pesticide use, soil erosion, and soil carbon are considered both production inputs and outputs. Table 3 provides an overview of these environmental simulation tools available within AgBizEnvironment, their outputs, and their applicability in producer-decision support frameworks.

Using the AgBizEnvironment module and associated environmental calculators, we explored the economic and environmental tradeoffs for switching to a conservation management practice for the winter wheat-fallow rotation. From AgBizProfit we calculated the change in farm-level net returns in the mid-Columbia region of switching to no-till (which is a more conservation-oriented, water conserving management practice) from conventional tillage. No-till has lower variable costs and labor requirements given the absence of the tillage operations pre- and post-harvest. However herbicide applications increase under no-till management in order to control weeds that would otherwise be managed with tillage, and equipment (airseeded) costs increased. Based on research trials, wheat yields in this micro region are essentially the same between the two systems, at about 63 bu./acre. This yield exceeds the 49.5 bu./acre used in the previous example which was estimated from the 2007 Ag Census data. We opted to use the higher research trial yields for the AgBizEnvironment since it reflects the conditions in this smaller micro-region (Table 3).

For the baseline scenario, since the yields and revenues were taken to be the same between the two systems, variation in net returns is due to costs. Under this baseline scenario, net returns for no-till exceed the net returns for conventional tillage by approximately $\$ 29$ per acre, or alternatively the yield advantage from conventional tillage would need to be about 6-7 bu./acre greater than no-till to equalize the net returns (Way 2015). So why do we not see a much larger adoption rate for the no-till management? In part, the answer may reside with combination of risk and expertise. At this point in the software development, AgBizProfit does not incorporate risk as it relates to management expertise.

Environmental impacts of concern also could include GHG emissions and possible soil erosion. These impacts were calculated using the COMET-Farm model for calculating changes in nitrous oxide and soil carbon equivalents only and the 
Table 3 Summary of the environmental tools available with AgBizEnvironment

\begin{tabular}{l|l|l|l}
\hline Simulation tool & Environmental factor & $\begin{array}{l}\text { Production input or } \\
\text { output }\end{array}$ & Source \\
\hline $\begin{array}{l}\text { Environmental } \\
\text { Impact Quotient } \\
\text { (EIQ) Value }\end{array}$ & Pesticides & Both & $\begin{array}{l}\text { http://www.nysipm. } \\
\text { cornell.edu/ } \\
\text { publications/eiq/ } \\
\text { equation.asp }\end{array}$ \\
\hline $\begin{array}{l}\text { Cool Farm Tool } \\
\text { (CFT) }\end{array}$ & $\begin{array}{l}\text { Greenhouse gas } \\
\text { emissions/Carbon } \\
\text { Sequestration }\end{array}$ & Output & $\begin{array}{l}\text { https://www. } \\
\text { coolfarmtool.org }\end{array}$ \\
\hline COMET-Farm & $\begin{array}{l}\text { Greenhouse gas } \\
\text { emissions/Carbon } \\
\text { Sequestration }\end{array}$ & Output & $\begin{array}{l}\text { http://cometfarm.nrel. } \\
\text { colostate.edu }\end{array}$ \\
\hline $\begin{array}{l}\text { Universal Soil Loss } \\
\text { Equation (USLE) }\end{array}$ & Soil Erosion & Both & $\begin{array}{l}\text { http://www.ars.usda. } \\
\text { gov/Research/docs. } \\
\text { htm?docid=10626 }\end{array}$ \\
\hline
\end{tabular}

Universal Soil Loss Equation (USLE) for estimating changes in soil erosion. Our preliminary results indicate a net gain of 0.2 tons soil carbon $\left(\mathrm{CO}_{2}\right.$ equv/yr./acre $)$ from the no-till relative to conventional tillage. There is no accounting for carbon dioxide emissions in the COMET-Farm results since this model does not adjust for changes in energy use. COMET-Farm reflects climate and soil models and thus accounts only for the nitrous oxide and soil carbon activity. With respect to soil erosion, the potential average soil loss for conventional tillage is 5.19 tons/acre/year, and for no-till practice the average soil loss is approximately 1.04 tons/acre/yr. Thus no-till is environmentally preferred over conventional tillage in these two dimensions.

It is noted that the long term average soil loss (5.19 tons/acre/year) for the conventional tillage on this farm, with slopes of $7-15 \%$ and Walla Walla silt loam soil type, exceeds the tolerable soil loss limit for maintaining productivity (5.0 tons/ acre/year). This brings into question the ability of the conventional tillage farm to continue to maintain yields equivalent to the no-till system. Under a multi-year net returns model, we would likely see yields fall relative to a multi-year no-till system and thus the gap in net returns would increase over time.

This example illustrates the approach to quantifying the economicenvironmental tradeoffs associated with alternative management practices and lays the groundwork for monitoring changes in soil carbon or other environmental outcomes that could be used in environmental or carbon accounting policies. What remains in future research is to link the climate changes and projected yield changes that are generated through AgBizClimate to the environmental outcomes that are generated through AgBizEnvironment and integrate with the economic and financial modules for a fully integrated decision-support framework for growers. 


\section{Toward Landscape-Scale Tradeoff Analysis: Linking to the TOA-MD Platform}

This section briefly discusses how farm-level data collected with a farm-level software tool such as AgBiz Logic could be combined with landscape-scale data to support regional policy analysis using a framework called TOA-MD (Tradeoff Analysis Model for Multi-dimensional Impact Assessment). We briefly describe the TOA-MD model, and discuss its data requirements and how those could be supported by data generated from AgBiz Logic. Also see Antle et al. (2016) for further discussion and an example of the use of the TOA-MD model for analysis of climate smart agriculture.

The TOA-MD model ${ }^{4}$ was designed to simulate technology adoption and impacts of climate change or changes in other external drivers within a population of heterogeneous farms. The TOA-MD framework is applied to farmers or growers who choose between the production system currently in use, which in this case would be the winter wheat fallow system, and an alternative production system such as annual cropping (winter wheat camelina), with the choice of system based on the distribution of expected economic returns in the regional farm population.

Unlike the AgBizLogic platform, TOA-MD is a model of a farm population, not a model of an individual or "representative" farm, and therefore TOA-MD can simulate an adoption rate for a region (i.e., the proportion of farms that would switch to the alternative production system). TOA-MD is based on a statistical description of the population of farms. Accordingly, the fundamental parameters of the model are population statistics - means, variances and correlations of the economic variables in the models and the associated outcome variables of interest. With suitable biophysical and economic data, these statistical parameters can be estimated with observational data for a production system in use, combined with experimental, modeled or expert data for a new system that is not yet in use and thus not observable.

The analysis of technology adoption and its impacts at the regional scale depends critically on how the effects of the new technology interact with bio-physical and economic conditions faced by farm decision makers. A key element in the TOA-MD analysis is reliable estimates of the effect of the new "technology" (i.e., the changes in the farming system that farmers could adopt) on the farming system's productivity and profitability. This information can come from various sources, including from formal crop and livestock simulation models, from experimental or observational data such as the information that can be obtained from a set of growers using AgBizLogic, or from expert judgment.

The TOA-MD model can be used for what Antle et al. (2014) describe as "adoption-based tradeoffs". Adoption-based tradeoffs occur when the adoption rate of a technology changes in response to an economic incentive or other factor affecting technology adoption. An important example of an adoption-based tradeoff is the

\footnotetext{
${ }^{4}$ See http://tradeoffs.oregonstate.edu.
} 
analysis of GHG mitigation through soil carbon sequestration that occurs when farmers are offered a contract to sequester soil carbon (e.g., see Antle and Stoorvogel 2008). In this type of analysis, the prices faced by the farmers for outputs and inputs are held constant, so the observed changes in behavior are induced by the incentive provided to change management in ways that increase the buildup of the soil carbon. The adoption can also be induced from changes in climate that occurs over a longer time frame.

\section{Data Requirements for the TOA-MD Model and How It Links to Farm-Scale Decision Support Tools}

The parameters of the TOA-MD model are the means, variances and co-variances (or correlations) of the economic returns to each production system being represented in the analysis, and these statistical parameters of the other outcomes of interest, e.g., environmental outcomes such as the change in soil carbon. These statistics represent the farm population of interest, thus the data to be used are ideally obtained from a statistically representative sample of the population of farms and collected over a long enough period of time (e.g., multiple growing seasons) so that statistical methods can be used to account for seasonal variation and other factors that could affect the observed outcomes. The data can be grouped into the following categories:

(i) prices, outputs and costs of production of each production activity;

(ii) farm characteristics, including farm size, family size, and non-agricultural income; and

(iii) other relevant environmental or social outcomes.

The conventional way to obtain the farm production data is to conduct a survey, such as the surveys done periodically by government agencies (e.g., agricultural census or other statistical surveys such as the Agricultural Resource Management Survey in the United States or the Farm Accountancy Data Network data collected in European Community countries). There are limitations to these kinds of data. One is that these data are often collected periodically, e.g., the U.S. agricultural census is carried out on 5-year intervals, and then only made available to researchers with a substantial delay of a year or more. Another major limitation is that these data often lack sufficient detail, particularly for management decisions such as fertilizer and chemical use, machinery use, and agricultural labor. A third limitation is that these surveys can be extremely expensive both for respondents (e.g., to complete large elaborate questionnaires) and for organizations collecting the data (e.g., to employ enumerators, data entry workers, quality control specialists, etc.).

A tool like $\mathrm{AgBiz}$ Logic could be utilized to provide higher quality, more timely data at lower cost. As portrayed in Fig. 1, a data system that linked farm management software to a confidential database could provide near real-time data on man- 
agement decisions, and do so for a statistically representative "panel" of farm decision makers over time. Moreover, the level of detailed management data utilized by $\mathrm{AgBiz}$ Logic would provide the needed level of detail for implementation of analysis using a tool such as TOA-MD. Also, users of AgBiz Logic would have every incentive to enter accurate information because they would be using this information to make their actual management decisions. Finally, a tool like $A g B i z$ Logic provides a user-friendly, efficient way for farmers to enter data, thus substantially reducing the cost of data collection.

Several considerations need to be incorporated to facilitate a linkage between AgBiz Logic and the TOA-MD framework. First, a statistically representative group of farms would need to be identified who would agree to use $\mathrm{AgBiz}$ Logic and allow their data to be used in a landscape scale analysis. This would involve a sampling process similar to identifying a sample of farms for a farm-level economic survey. Second, software would need to be designed to transmit and assemble the individual farm data into a database that could subsequently be used to estimate TOA-MD parameters while maintaining confidentiality of individual producers. Note that data would need to be collected over multiple growing seasons in most cases to account for crop rotations and other dynamic aspects of the farming system. Farm household characteristic data could be collected as a part of AgBiz Logic, or could be collected using a separate survey instrument. Environmental and social outcome data collection would need to be tailored to the specific type of variable. For example, measurement of soil organic matter could require infield soil sampling and laboratory analysis, possibly combined with modeling, or the use of specialized sensors.

In addition it is important to project from current biophysical and socioeconomic conditions into plausible future conditions. This is currently being done on a global scale using new scenario concepts called "Representative Concentration Pathways" and "Shared Socio-Economic Pathways." To translate these future pathways into ones with more detail needed for agricultural assessments, "Representative Agricultural Pathways" are being developed (Valdivia et al. 2015). The data acquired through tools such as $\mathrm{AgBiz}$ Logic can be combined with these future projections to implement regional integrated assessments using the new methods developed by the Agricultural Model Inter-comparison and Improvement Project (Antle et al. 2015).

\section{Conclusions}

The use of a decision support tools such as $\mathrm{AgBiz}$ Logic can provide farmers better information on the relative impacts of adapting to a change as reflected in changes in future climate conditions, changes in future policies, prices, and costs or changes in terms of lease arrangements. It can also be used by researchers to understand how decisions about new programs, management options, technologies and varieties may impact a producer's net returns and ultimately his/her choices with respect to adoption of alternative management practices or cropping systems. By 
Accumulated Net Returns for a Ten-Year Crop-Share Lease

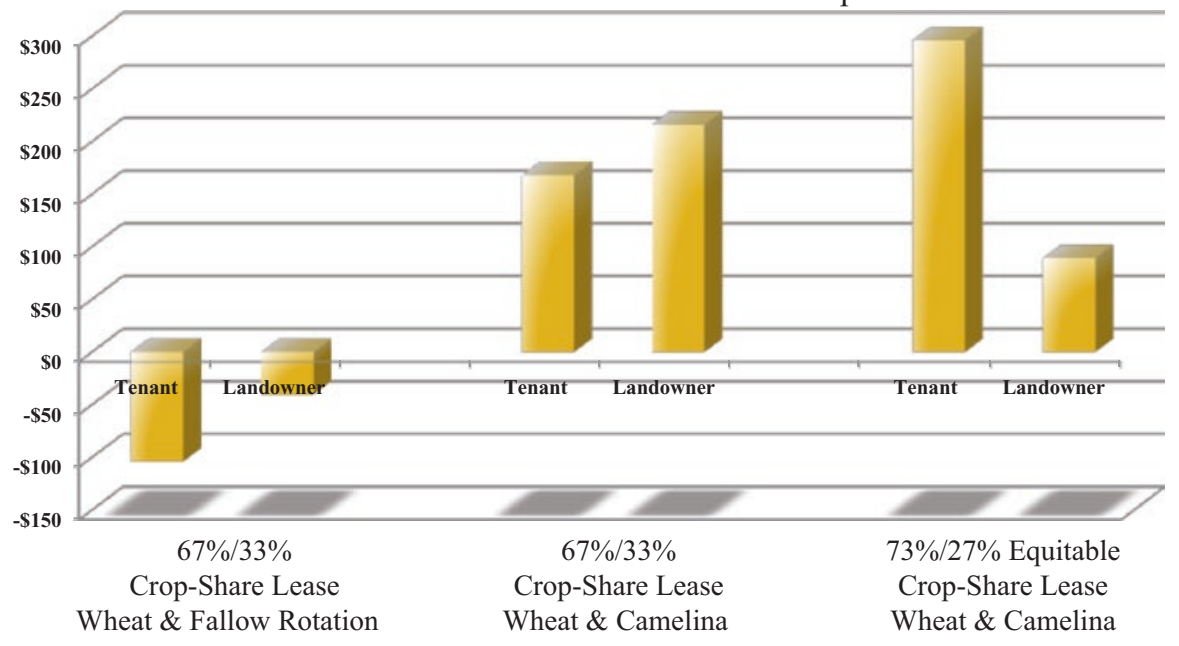

Fig. 4 AgBizLease: results when crop-share leases for a wheat and fallow rotation change to an annual cropping system

incorporating both climate change and environmental outcomes, these decision tools can be used to evaluate climate smart options at the farm-scale.

The examples in this paper illustrate how an integrative decision support tool that is properly fine-tuned for the specific applications can better inform growers and land owners of how changes in climate will impact their operations and their environmental outcomes. AgBizClimate was used to show the impacts of climate change to wheat production. AgBizProfit was used to show adaptation strategies to an annual cropping system. AgBizFinance can be used to show the feasibility of purchasing additional equipment to farm the annual cropping system. AgBizLease showed how changing to an annual cropping system also changes the sharing of the crop, and AgBizEnvironment showed the tradeoffs of economic returns to environmental impacts (Fig. 4).

A software tool like AgBiz Logic could also be utilized to provide higher quality, more timely data for landscape-scale and regional technology assessment. As portrayed in Fig. 1, a data system that linked farm management software to a confidential database could provide near real-time data on management decisions, and do so for a statistically representative "panel" of farm decision makers over time. Moreover, the level of detailed management data utilized by AgBiz Logic would provide the needed level of detail for implementation of analyses using a tool such as TOA-MD. Users of AgBiz Logic would have every incentive to enter accurate information because they would be using this information to make changes to future management decisions. Finally, a tool like AgBiz Logic provides a user-friendly efficient way for farmers to enter data, thus substantially reducing the cost of data collection. 
Acknowledgements This material is based upon work supported by the National Institute of Food and Agriculture, U.S. Department of Agriculture, under award numbers 2011-68002-30191, 2014-51181-22384 and 2012-38420-30208 (Regional Approaches to Climate Change - Pacific Northwest Agriculture; Developing a Sustainable Biofuels System in the PNW: Economic, Policy and Commercialization Analysis; National Needs Graduate and Postgraduate Fellowship Grants Program (NNF) - Graduate Education in the Economics of Mitigating and Adapting to Climate Change:Evaluating Tradeoffs, Resiliency and Uncertainty using an Interdisciplinary Platform), The Northwest Climate Hub, the Agricultural Model Intercomparison and Improvement Project (AgMIP), and Oregon Agricultural Experiment Station.

\section{Appendix A: How AgBiz Logic Works and Its Web-Based Presence}

To begin an AgBizClimate analysis, name this scenario, add notes, and select budgets from your existing database.

Name of Scenario:

Climate Change Impacts on Current and Potential Annual Cropping System

Notes for this Scenario:

Observing the before and after effects of climate change on per acre net returns of growing a winter wheat \& fallow rotation and a winter wheat \& Camelina annual cropping system in 2040

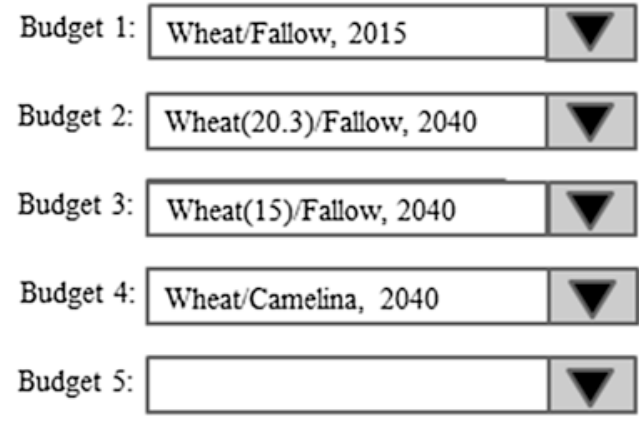

Fig. 5 Naming a scenario, inserting notes for a scenario and selectin $A B L$ budgets 


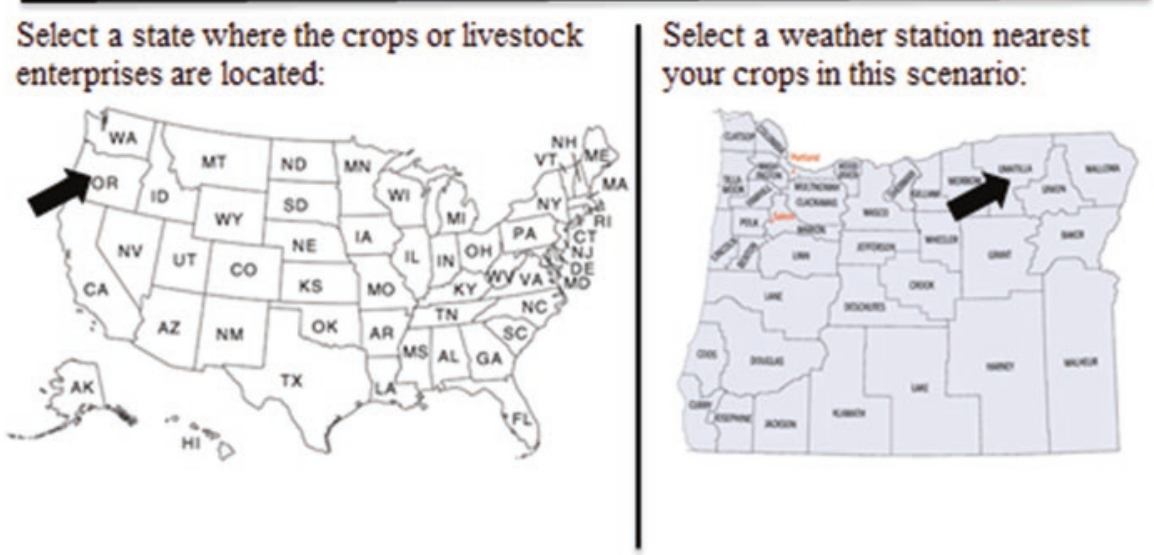

Fig. 6 Selecting Oregon and Umatilla county as the state and county with the closer weather station to crops grown

WHEAT yields will most likely be impacted by climate change. Select the 3 most important weather variables from the list below that will impact yields or quality of the crop in this scenario.
- Seasonal mean temperature
- Number of days above freezing
- Number of nights below freezing
- Number of warm nights
- Number of consecutive extremely hot days
- Number of consecutive extremely cold days
- Accumulated growing degree days
- Accumulated chilling hours
- 24-hour temperature range (night v. day)
- Number of consecutive wet days
- Number of consecutive dry days
- Accumulated seasonal precipitation
- Snowpack

Fig. 7 Weather variables that will likely impact yields or quality of products for crop and livestock enterprises 
Based on your selected weather variables and weather station, the following are projected impacts from climate change.

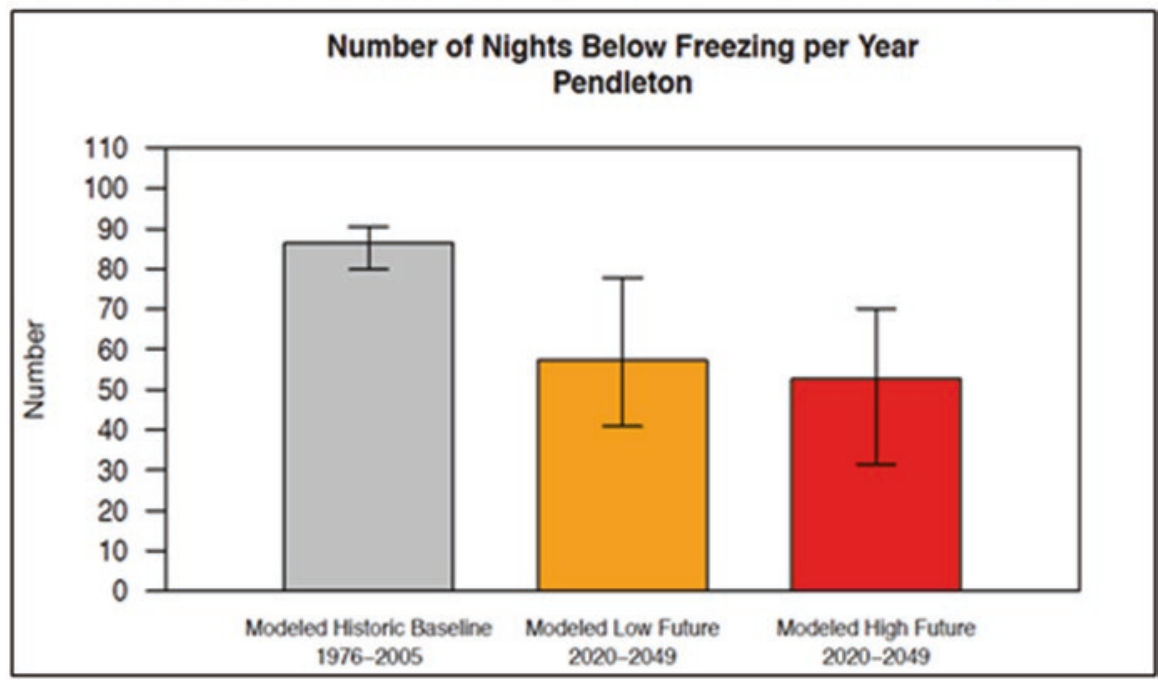

Based on this information, How do YOU think these climate changes will affect your WHEAT yields?: $20 \%$ C Change

Fig. 8 Weather variables that will likely impact yields or quality of products for crop and livestock enterprises

Based on your selected weather variables and weather station, the following are projected impacts from climate change.

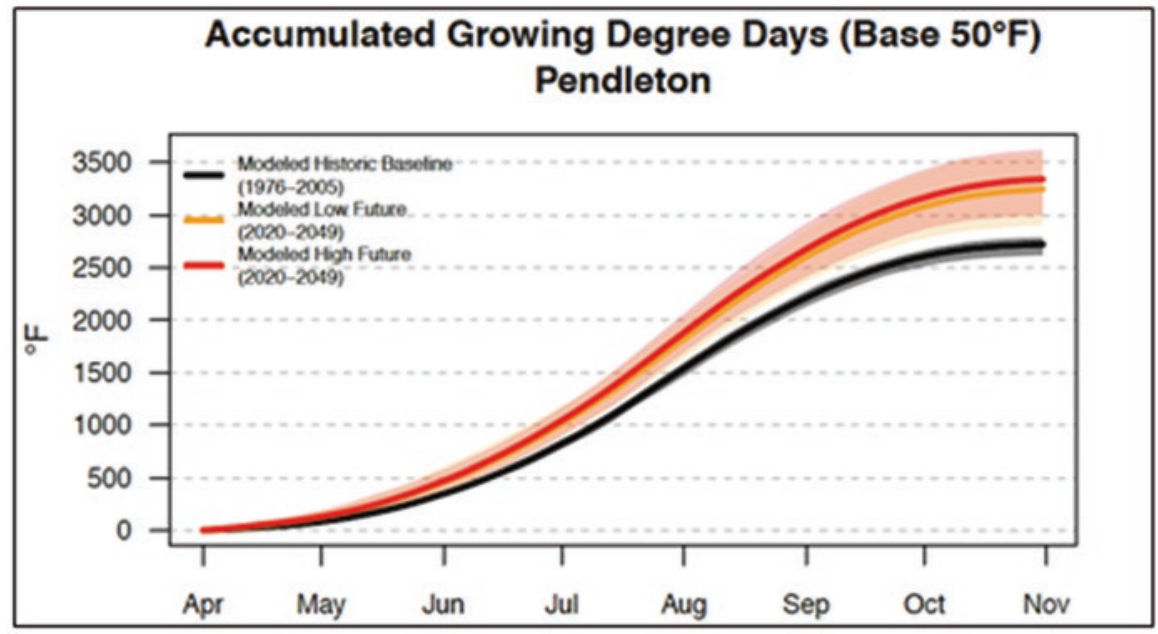

Based on this information, How do YOU think these climate changes will affect your WHEAT yields?: $15 \%, \mathbf{A}$ Change

Fig. 9 Weather variables that will likely impact yields or quality of products for crop livestock enterprises 
Based on your selected weather variables and weather station, the following are projected impacts from climate change.

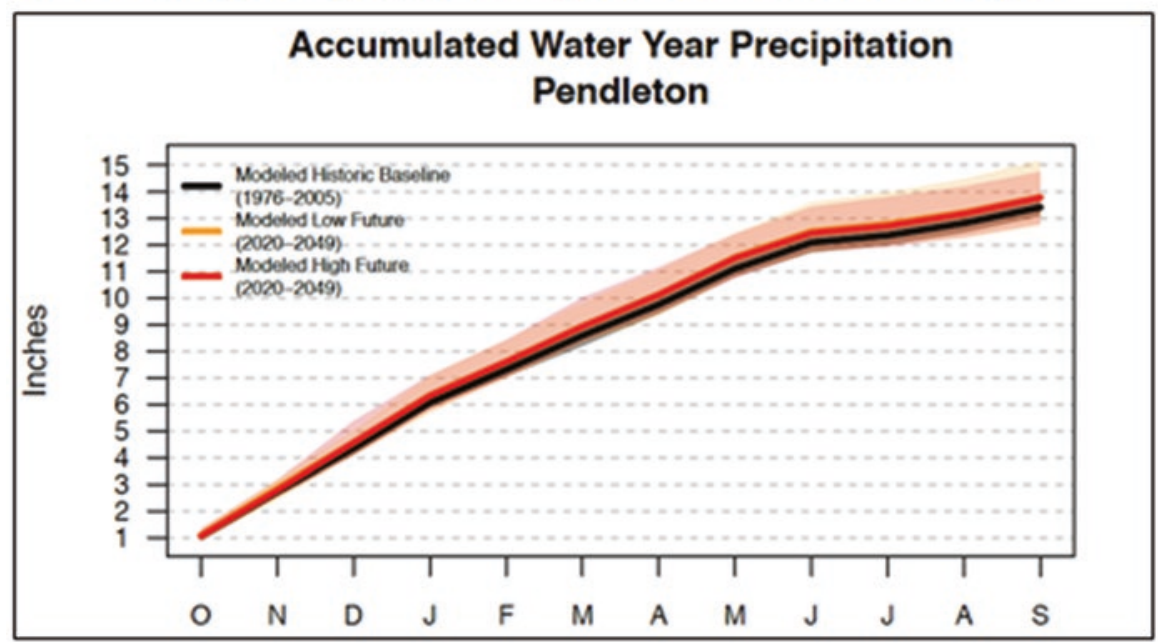

Based on this information, How do YOU think these climate changes will affect your WHEAT yields?: $25 \%$ A Change

Fig. 10 Weather variables that will likely impact yields or quality of products for crop and livestock enterprises

\begin{tabular}{|c|c|c|}
\hline & $\begin{array}{c}\text { Winter Wheat } \\
\text { Owned }\end{array}$ & $\begin{array}{l}\text { Wheat Wheat } \\
\text { Leased }\end{array}$ \\
\hline Crop Modeling & $+20.3 \%$ & $+20.3 \%$ \\
\hline Grower Focus Groups & $+15.0 \%$ & $+15.0 \%$ \\
\hline Weather Var. 1 & $+20.0 \%$ & $+20.0 \%$ \\
\hline Weather Var. 2 & $+15.0 \%$ & $+15.0 \%$ \\
\hline Weather Var. 3 & $+25.0 \%$ & $+25.0 \%$ \\
\hline Your Changes & $+20.3 \%$ & $+20.3 \%$ \\
\hline
\end{tabular}

Fig. 11 Weather variables that will likely impact yields or quality of products for crop and livestock enterprises 
Seavert, C. F., 1999. Negotiating New Lease Arrangements with the Transition to Direct Seed Intensive Cropping Systems. PNW Direct Seed Conference, Spokane, WA. http://pnwsteep. wsu.edu/directseed/conf99/DSPRSEA.htm\#Table1

Seavert, C., Steven Petrie, and Sandy Macnab. 2012. Enterprise Budget: Wheat (Winter) Following Fallow, Direct Seed, 12-18 inch Precipitation Zone, North Central Region. AEB 0036. http:// arec.oregonstate.edu/oaeb/files/pdf/AEB0036.pdf

United States Department of Agriculture (USDA) Agricultural Research Service (ARS). (n.d.) Universal Soil Loss Equation (USLE).. http://www.ars.usda.gov/Research/docs. htm?docid= 10626

United States Department of Agriculture. 2007. 2007 Census of Agriculture, State and County Reports.. http://www.agcensus.usda.gov/Publications/2007/Full_Report/ Volume_1,_Chapter_2_County_Level/

U.S. Government Accountability Office. 2014. Climate Change: USDA's Ongoing Efforts Can Be Enhanced with Better Metrics and More Relevant Information for FarmersGAO-14-755: Published: Sep 16, 2014. Publicly Released: Oct 16, 2014. http://www.gao.gov/products/ GAO-14-755

Valdivia, R.O., J.M. Antle, C. Rosenzweig, A.C. Ruane, J. Vervoort, M. Ashfaq, I. Hathie, S. Homann-Kee Tui, R. Mulwa, C. Nhemachena, P. Ponnusamy, H. Rasnayaka and H. Singh. 2015. Representative Agricultural Pathways and Scenarios for Regional Integrated Assessment of Climate Change Impact, Vulnerability and Adaptation. C. Rosenzweig and D. Hillel, eds. Handbook of Climate Change and Agroecosystems: The Agricultural Model Intercomparison and Improvement Project Integrated Crop and Economic Assessments, Part 1. London: Imperial College Press.

Way, Jenna. 2015. Linking Farm Profits and Environmental Quality Outcomes for Different On-Farm Conservation Practices. A Project submitted to Oregon State University in partial fulfillment of the requirements for the degree of Master of Science.

Open Access This chapter is distributed under the terms of the Creative Commons AttributionNonCommercial-ShareAlike 3.0 IGO license (https://creativecommons.org/licenses/by-nc-sa/3.0/ igo/), which permits any noncommercial use, duplication, adaptation, distribution, and reproduction in any medium or format, as long as you give appropriate credit to the Food and Agriculture Organization of the United Nations (FAO), provide a link to the Creative Commons license and indicate if changes were made. If you remix, transform, or build upon this book or a part thereof, you must distribute your contributions under the same license as the original. Any dispute related to the use of the works of the FAO that cannot be settled amicably shall be submitted to arbitration pursuant to the UNCITRAL rules. The use of the FAO's name for any purpose other than for attribution, and the use of the FAO's logo, shall be subject to a separate written license agreement between the FAO and the user and is not authorized as part of this CC-IGO license. Note that the link provided above includes additional terms and conditions of the license.

The images or other third party material in this chapter are included in the chapter's Creative Commons license, unless indicated otherwise in a credit line to the material. If material is not included in the chapter's Creative Commons license and your intended use is not permitted by statutory regulation or exceeds the permitted use, you will need to obtain permission directly from the copyright holder.

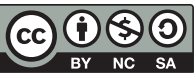

